\title{
Políticas e desafios da educação TÉCNICO-PROFISSIONAL EM MoÇAMBIQUE
}

\author{
Policies and challenges of professional technical education in Mozambique
}

Políticas y desafíos de la educación técnica y profesional en Mozambique

RESUMo O presente trabalho de pesquisa tenciona discutir os fundamentos da política da educação técnico-profissional em Moçambique e seus desafios. Surgem muitas vozes a criticar o sistema da educação moçambicana e uma delas tem a ver com o contributo dos formandos que pouco se faz sentir na vida prática. Assim, busca-se responder à pergunta: Quais são as políticas e os desafios do ensino técnico profissional moçambicano? Logo, objetiva-se analisar as políticas e desafios do ensino técnico-profissional em Moçambique. No que concerne à metodologia, recorreu-se à pesquisa teórica, que teve como fundamento as leituras, interpretações e análise de diferentes literaturas, artigos, bem como, textos filosóficos que se referem ao tema em discussão. Hoje, em Moçambique, cada vez mais aproxima-se a ideia de fazer que a educação leve os indivíduos, não só à teorização dos conhecimentos, mas à sua praticidade. É deste modo que as políticas de ensino técnico- profissional (ETP) parecem estar, mas centralizada na questão da empregabilidade, pois, o governo está preocupado com a escassez de mão de obra especializada para satisfazer a demanda dos grandes projetos envolvidos na exploração de recursos minerais no país e vê o ETP como única saída. Entretanto, há alguns desafios, como: a insuficiência no provimento de professores; inadaptação dos currículos às atuais necessidades do mercado de trabalho; falta de capacidade de gestão/supervisão; a pouca autonomia e má gestão das instituições; orçamentos insuficientes; altas taxas de repetição, de desistência e insucesso e o elevado custo por aluno do ensino técnico profissional.

Palavras-Chave: ENSINO TÉCNICO. ENSINO TÉCNICO PROFISSIONAL. TRABALHO. MOÇAMBIQUE.

ABSTRACT This research aims to discuss the fundamentals of professional technical education policy in Mozambique and its challenges. There are many voices criticizing the Mozambican education system and one of them has to do with the contribution of the trainees that little is felt in the practical life. Thus, it is sought to answer the question: What are the policies and challen-

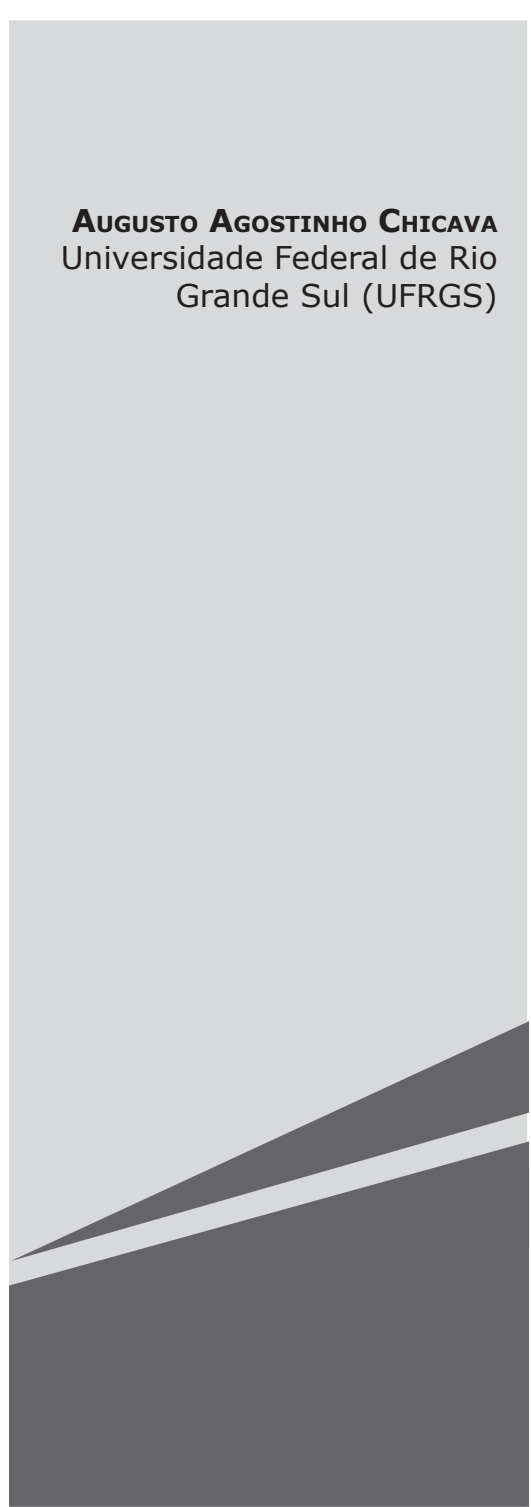


ges of Mozambican vocational technical education? Therefore, it aims to analyze the policies and challenges of vocational technical education in Mozambique. With regard to methodology, we used theoretical research based on the readings, interpretations and analysis of different literatures, articles as well as philosophical texts that refer to the topic under discussion. Nowadays, in Mozambique, the idea of making education lightens individuals, not only to theorization of knowledge, but also to practicality. It is in this way that vocational technical education (ETP) policies seem to be more centralized in the question of employability, because the government is worried about the shortage of skilled labor to satisfy the demand of large projects involved in the exploitation of mineral resources in the country and sees ETP as the only way out. However, there are some challenges, such as: insufficient provision of teachers; maladaptation of curricula to current labor market needs; lack of management/supervision capacity; poor autonomy and mismanagement of institutions; insufficient budgets; high rates of repetition, withdrawal and failure and the high cost per student of vocational technical education.

KEY WORDS: TECHNICAL EDUCATION. PROFESSIONAL TECHNICAL EDUCATION. JOB. MOZAMBIQUE

RESUMEN Este trabajo de investigación pretende discutir los fundamentos de la política de educación técnica y profesional en Mozambique y sus desafíos. Hay muchas voces que critican el sistema educativo mozambiqueño y una de ellas tiene que ver con la contribución de los alumnos que tiene poco sentido en la vida práctica. Por lo tanto, buscamos responder la pregunta: ¿Cuáles son las políticas y los desafíos de la educación técnica profesional de Mozambique? Por lo tanto, el objetivo es analizar las políticas y los desafíos de la educación técnica y profesional en Mozambique. En cuanto a la metodología, se recurrió a la investigación teórica, que se basó en las lecturas, interpretaciones y análisis de diferentes literaturas, artículos, así como textos filosóficos que hacen referencia al tema en discusión. Hoy, en Mozambique, la idea de hacer que la educación lleve a las personas no solo a la teorización del conocimiento, sino también a su practicidad, se está acercando cada vez más. Así es como parecen ser las políticas de educación técnico-profesional (ETP), pero centradas en el tema de la empleabilidad, ya que al gobierno le preocupa la escasez de mano de obra calificada para satisfacer la demanda de grandes proyectos involucrados en la explotación de recursos. minerales en el país y ve ETP como la única salida. Sin embargo, existen algunos desafíos, tales como: provisión insuficiente de maestros; inadecuación de los planes de estudio a las necesidades actuales del mercado laboral; falta de capacidad de gestión / supervisión; la pobre autonomía y el mal manejo de las instituciones; presupuestos insuficientes; altas tasas de repetición, deserción y fracaso y el alto costo por estudiante de educación técnica vocacional.

Palavras clave: Educación técnica. Educación técnica profesional. Yo trabajo Mozambique. 


\section{INTRODUÇ̃̃o}

Segundo Azevedo e Abreu (2007), depois da guerra civil e das eleições de 1994, a educação foi encarada como uma prioridade nacional, com destaque para o ensino elementar. O sistema educativo nacional moçambicano era regulado por uma Lei de Bases, de 1983. Em Agosto de 1995, foi aprovada pelo Governo uma nova política nacional de educação, reconfirmada pelo "Plano Nacional de Desenvolvimento do Sistema Educativo", discutido com os doadores em Setembro de 1997, em que se definiram as grandes orientações para os anos vindouros, a saber: melhorar o acesso à educação e a qualidade do ensino. Já nesse momento, foi atribuído ao Ensino Técnico-Profissional um papel muito significativo, afirmando-se como prioridade reabrir e criar escolas de artes e ofícios e elementares de agricultura e pecuária, e incentivar outras iniciativas neste domínio, por forma a promover o autoemprego. Das Escolas de Artes e Ofícios (EAO) esperava-se um papel determinante na "reativação do tecido produtivo nas zonas rurais e na fixação das populações" (MINISTÉRIO DA EDUCAÇÃO, 1995^, apud AZEVEDO e ABREU, 2007, p. 25). Tais escolas tinham caraterísticas bem específicase contribuiram significativamente para o bem-estar da população, conforme destacam Azevedo e Abreu (2007):

As EAO eram escolas-oficinas e tinham por finalidade principal dar aos seus alunos, quase sempre população autóctone, uma preparação profissional prática, a que se juntava alguma formação académica, bastante elementar, equivalente ao primeiro grau, ou seja, a terceira classe da instrução primária. Os oficiais deles saídos, viam em geral melhorada a sua situação económica, diferenciando-se mesmo dos trabalhadores rurais, socialmente mais desfavorecidos. A primeira escola foi criada em 1907, na llha de
Moçambique, pelos padres Salesianos, e oferecia formação nas áreas das artes gráficas e da carpintaria. Desta escola-oficina saía boa parte do material impresso que circulava, ao tempo, em Moçambique" (AZEVEDO e ABREU, 2007, p. 26)

Sabe-se que o sistema de educação técnico-profissional Moçambicano é oferecido-sobretudo por escolas públicas e centros de formação administrados pelos diferentes ministérios. Há pouco tempo, alguns provedores privados entraram no mercado e ofereceram programas especializados de formação aos seus clientes do setor privado (principalmente novos investidores estrangeiros), mas estes programas ainda só beneficiam uma minoria de alunos no sistema de educação técnico-profissional (BROUWER e BRITO, 2010, p.10). Pela sua natureza e enfoque, o ensino técnico-profissional (ETP) enquadra-se no conceito mais amplo de Educação Profissional, o qual envolve como provedores o governo e outros parceiros (PLANO ESTRATÉGICO DA EDUCAÇÃO, 2012-2016, p. 90).

Segundo Macamo (2015), ETP de qualidade envolve elevados custos. Comparando ao Ensino Secundário Geral (ESG) a algumas especialidades do Ensino Superior, o custo por aluno do ETP é mais alto. Porém, apesar de ser alocado, a este tipo de ensino, uma parte considerável do orçamento para o setor de Educação, não é suficiente para garantir as condições necessárias à progressão das reformas já iniciadas. A fim de manter a sustentabilidade financeira do ETP, assegurar a sua qualidade e expansão, o Ministério de Educação de Moçambique tem redefinido os critérios de financiamento e aumenta a contribuição do setor privado por meio do envolvimento das comunidades e das próprias famílias. Assim sendo, este novo século (XXI), inicia-se com o ressurgimento do Ensino Técnico-Profissional, o qual passou pela preparação de uma nova estratégia do Ensino Técnico-Profissional e pelo início da Reforma da Educação Profissional (REP). 
Visando a concretização deste estudo, foram utilizados os procedimentos metodológicos da pesquisa teórica e qualitativa, fundamentando-se em leituras, interpretações e análise de diferentes manuais e textos científicos. Também foi usado o método hermenêutico, por meio de recursos didáticos, fazendo uma análise aprofundada de diferentes abordagens que discorrem a respeito da questão da educação moçambicana, em diversos âmbitos. Valeu-se ainda da pesquisa bibliográfica, mediante consultas a estudos já publicados, com o intuito de também proceder a uma abordagem sobre atual cenário da educação moçambicana. A pesquisa foi o resultado do trabalho desenvolvido, pelo autor, durante o curso de mestrado.

\section{CONCEPÇÃo RELACIONAL ENTRE EDUCAÇÃO E TRABALHO}

Em contexto do mundo capitalista marcado pela revolução tecnológica acelerada, em que a força do trabalho é uma mercadoria, cujo preço depende cada vez mais de habilidades adquiridas nos bancos escolares, os trabalhadores encaram a educação como a senha necessária para ingresso e permanência no emprego. A escola continua a ser vista como a porta de entrada para o mundo do trabalho e condição para a sobrevivência.

A educação e trabalho fazem parte da mesma dimensão e podemos inferir como uma dimensão humana, ou seja, essas duas categorias dizem respeito somente ao ser do homem. Segundo Karl Marx (1964), trabalho manual (prática) e trabalho intelectual (teoria) deveriam associar-se, ou seja, combinação entre o trabalho produtivo e a educação (politécnica), considerando que a primeira finalidade da vida é a manutenção e a reprodução de si mesma. Desse modo, Gramsci (2004) introduz o conceito da escola unitária, que procura salvaguardar a relação entre o trabalho manual e trabalho intelectual, ou seja:

A crise terá uma solução que, racionalmente, deveria seguir esta linha: escola única inicial de cultura geral, humanista, formativa, que equilibre de modo justo o desenvolvimento da capacidade de trabalhar manualmente (tecnicamente, industrialmente) e o desenvolvimento das capacidades de trabalho intelectual. (GRAMSCI, 2004, p.33).

Entretanto, a educação pode ser entendida como processo de formação da personalidade do homem para a vida e trabalho na sociedade, na medida que se torna um suporte na efetivação do homem na intervenção e transformação do mundo, isto é:

a escola unitária (...) deveria assumir a tarefa de inserir os jovens na atividade social, depois de tê-los elevados a um certo grau de maturidade e capacidade para criação intelectual e prática e a uma certa autonomia na orientação e na iniciativa (GRAMSCl, 2004, p. 36).

Assim sendo, há uma necessidade de distinguir educação técnica e tecnicista. Isto é, educação técnica refere-se aos processos de manipulação do mundo material; e a educação tecnicista por sua vez enfatiza a predominância da mecanicidade dos mesmos. Entretanto, educação como a prática técnica é trabalho por seus procedimentos burocráticos e também por sua dinâmica. Errôneo pensar educação distinto do trabalho, pois, a educação aumenta a produtividade e produz o conhecimento técnico exigido pelo acelerado crescimento econômico no mundo de trabalho.

Portanto, na concepção da educação prática, a escola procura valorizar as ações didáticas e a mesma tem maior probabilidade de proporcionar ao educando apropriados métodos para o aprendizado e, aos professores, a possibilidade do desenvolvimento das competências necessárias para implementar as ações requeridas. Na mesma ordem de ideia, Gramsci (2004) salienta que devemos conceber o trabalho como um princípio edu- 
cativo, ou seja, o estudo é também trabalho e muito cansativo (GRAMSCI, 2004). E tendo em conta que o trabalho humaniza o homem.

No contexto moçambicano, a relação da educação e mundo de trabalho é marcada por um certo desnivelamento, ou seja, "nota-se um desfasamento entre as mudanças que ocorrem no mundo do trabalho e a o perfil do trabalhador ingresso nas Instituições da educação moçambicana" (GONÇALVES, 2015, p. 8). E, segundo o mesmo autor, um dos problemas desse desnivelamento entre educação e mundo de trabalho, no sistema educacional moçambicano, é a falta de escolas técnicas vocacionais e profissionais de educação terciária, o que se traduz no pouco número de trabalhadores com uma qualificação profissional que esteja em consonância com as mudanças no mundo do trabalho exigidas pelos empregadores.

\section{Políticas nacionais do ensino TÉCNICO-PROFISSIONAL EM MoÇAMBIQUe}

A missão das EP é qualificar profissionalmente adolescentes e jovens moçambicanos como núcleo de uma estratégia de desenvolvimento sócio-económico nacional que requer e repousa, em boa parte, na existência de uma mão-de-obra competente e apta a evoluir nos mais variados contextos profissionais e laborais. (Artigo no ${ }^{\circ} 1$ do Regulamento das Escolas Profissionais de Moçambique de 2003).

O ETP em Moçambique foi criado ainda no tempo colonial, ou seja, a lei colonial $n^{\circ}$ 2025, de 19 de julho de 1947, já vinha a reger o ensino técnico-profissional. E em 1948, criou-se a Direção Geral do Ensino Técnico Profissional (decreto lei $n^{\circ} 37.028$, de 25/08//48), que tinha como função conduzir o ensino agrícola, industrial e comercial (PINTO, 2012).

Entretanto, nessa ordem de ideia, no ano de 1975, surge, em Moçambique, o primeiro debate sobre o Ensino técnico, isto quando da realização do Seminário Nacional do Ensino Técnico, e, segundo Pinto (2012), era um cenário de uma rede escolar reduzida. Havia-insuficiente aparelhamento das instituições em material oficinal e instrumentalização de laboratórios, além de falta de pessoal docente e de técnicos habilitados, decorrentes da saída dos portugueses.

Esses cenários do Ensino Técnico também verificaram-se depois da independência, como procura ilustrar Pinto:

Mesmo depois da independência, verifica-se dispersão da responsabilidade, da direção e administração das áreas de formação e educação, assim como desarticulação e fraca interligação entre várias estruturas educacionais. Os princípios e os objectivos gerais eram diversos, não existia um perfil profissional, as ações realizadas não obedeciam a um plano único de formação de força de trabalho qualificada, não existia normas e princípios de equivalência, continuidade de estudos, diplomas e regulamentação diversa (SNE, 1985 apud PINTO, 2012, p. 5).

Um dos objetivos e prioridades do Governo Moçambicano (o programa quinquenal para o período 1995-1999) é a redução dos níveis de pobreza absoluta e melhoria de vida de sua população Educação, concretamente educação técnica, era a saída para se alcançar este objetivo. Com a aprovação da Política Nacional de Educação (PNE), em 1995, surge a necessidade de traduzir as intenções políticas para um quadro de ações e transformações por meio de um Plano Estratégico. E é a partir disso que surgiu o primeiro Plano Estratégico de Educação 1999-2003 (PEE I), o qual tinha como lema "Combater a Exclusão, Renovar a Escola". Caracterizou-se como sendo um plano centrado em prioridades, com opções limitadas, que se apoiou nos três pilares definidos pela Política Nacional de Educação, quais sejam: aumento do acesso e equidade; melhoria 
da qualidade e relevância do ensino; reforço da capacidade institucional do Ministério da Educação. O Plano Estratégico de Educação (PEE) propõe três principais objetivos para o sistema educativo: aumentar o acesso às oportunidades educativas para todos os moçambicanos e em todos os níveis do sistema; manter e melhorar a qualidade da educação, e por último desenvolver um quadro institucional e financeiro que possa, no futuro, sustentar as escolas e os alunos (PLANO ESTRATÉGICO DE EDUCAÇÃO 1999-2003, 1998).

Ainda no mesmo ano de 2005, surge outra mudança. Houve extinção dos Ministérios da Educação e da Cultura e foi criado o Ministério da Educação e Cultura, mantendo na sua gênese a estrutura Direção Nacional de Educação Técnico-Profissional e Vocacional (DINET). Por sua vez, a DINET teve a responsabilidade de elaborar o segundo Plano Estratégico da Educação 2005/2009 (PEE II), que tinha como objetivo redução da pobreza absoluta; assegurar a justiça e a equidade do gênero e a luta contra a propagação do HIV/ SIDA e a mitigação do seu impacto.

Como parte integrante do PEE I e do Plano de Ação para a Redução da Pobreza Absoluta (2001-2005), a estratégia do Ensino Técnico-Profissional em Moçambique (20022011), "Mais técnicos, novas profissões, meIhor qualidade", identifica as opções e ações prioritárias a serem implementadas visando ajustar o ETP aos desafios do desenvolvimento econômico de Moçambique.

Assim, esse documento destaca que o ETP tem como missão garantir aos cidadãos o acesso a uma formação científico-técnica altamente qualificada, para responder às necessidades do desenvolvimento econômico e social. Diz também que esse ensino técnico tem como visão a transformação num subsistema mais flexível, articulado, inovador, dinâmico, autônomo e sustentável, reconhecido, valorizado, comparticipado por todos os parceiros sociais, com capacidade de adaptação e com respostas às mudanças, acessível a todos, com oferta de programas de formação flexíveis, que promovam competências profissio- nais, relevantes, que preparem os indivíduos para o mundo de mercado e para a vida, que contribua para o Desenvolvimento dos Recursos Humanos de Moçambique e com um sistema de Avaliação e Certificação. E segundo Pinto (2010), os objetivos estratégicos vão ao encontro aos do Plano Estratégico da Educação 2012-2016 (PEE III).

Neste caso, realiza-se o segundo seminário Nacional do Ensino Técnico-Profissional, isto entre os dias 24 a 28 de maio de 2004, o mesmo tinha como objetivo de avançar na implementação da Estratégia do ETP (20022011). E que se pretendia lançar um debate estratégico sobre a reforma do Ensino Técnico-Profissional e conhecer possíveis opções para essa mesma reforma. Daqui resultou a discussão de uma nova visão mais abrangente do ETP e Formação Profissional, de uma busca de consenso sobre a reforma do sistema de ETP entre as entidades envolvidas (PINTO, 2010). Posteriormente, iremos discutir sobre esta reforma do ETP.

De acordo com a Política Nacional de Educação e Estratégias de Implementação, promulgada pelo Conselho de Ministros da República de Moçambique (Resolução $\mathrm{n}^{\circ}$ 8/95, de 22 de agosto de 1995), o Ensino Técnico tem a responsabilidade de formar os operários e técnicos necessários devidamente qualificados, para responder às necessidades de mão de obra qualificada para os diferentes setores econômicos e sociais do país.

Nessa ordem de ideia e perante a Resolução nº 8/95, de 22 de agosto de 1995, esse ensino encontra-se subdividido em três níveis: Ensino Técnico Elementar (ETE), Ensino Técnico Básico (ETB) e o Ensino Técnico Médio (ETM). O ETE faz-se após a conclusão do $1^{\circ} \mathrm{Grau}$ do Ensino Primário Geral ou para adultos, inclui disciplinas de formação geral e técnica, conferindo um nível escolar correspondente ao Ensino Primário Geral ou para adultos.

Ao contrário do antigos Planos (PEE I e PEE II), o Plano Estratégico da Educação 20122016 subdivide-se em dois níveis: o nível básico e nível médio, cada um com duração de três anos. Assim está expresso no PEE (2012-2016): 
O Ensino Técnico-Profissional estrutura-se neste momento em dois níveis: o nível básico e o nível médio, ambos com a duração de três anos, e é organizado por ramos: comercial, industrial e agrícola. O critério mínimo de ingresso é a conclusão da $7^{\mathrm{a}}$ classe para o nível básico, e, para o nível médio, a conclusão da $10^{a}$ classe do Ensino Secundário Geral ou do $3^{\circ}$ ano do nível básico do
Ensino Técnico-Profissional. Este nível de educação não é gratuito, havendo cobrança de propinas. O Ensino Técnico-Profissional está numa fase de reforma, com enfoque na introdução de um sistema educativo modular, seja ao nível básico, seja ao nível médio, que vai resultar em diferentes tipos de certificados (PLANO ESTRATÉGICO DA EDUCAÇÃO, 2012-2016, p. 14).

Quadro 1: Alunos matriculados nas escolas profissionais de Moçambique - 2006

\begin{tabular}{|c|c|c|c|c|c|c|c|}
\hline \multicolumn{3}{|c|}{ Escola } & \multicolumn{5}{|c|}{ Alunos matriculados - ciclos de formação } \\
\hline Nome & Provincia & Início & $2002 / 03$ & $2003 / 04$ & $2004 / 05$ & $2005 / 06$ & $2006 / 07$ \\
\hline Moamba & \multirow{3}{*}{ Maputo } & 2002 & \multicolumn{2}{|c|}{$178^{1}$} & 127 & 74 & 107 \\
\hline Magude & & 2004 & \multicolumn{2}{|c|}{ - } & 27 & 40 & 70 \\
\hline S. Francisco & & 2005 & & & - & 90 & 257 \\
\hline Inhamissa & \multirow{3}{*}{ Gaza } & 2002 & \multicolumn{2}{|c|}{196} & 91 & 118 & 66 \\
\hline Messano & & 2004 & \multicolumn{2}{|c|}{ _ } & 40 & 45 & 15 \\
\hline Mangunze & & 2004 & \multicolumn{2}{|c|}{ _ } & 36 & 22 & 11 \\
\hline $\begin{array}{l}\text { Domingos Sa- } \\
\text { vio }\end{array}$ & \multirow{5}{*}{ Inhamban } & 2003 & \multicolumn{2}{|c|}{120} & 120 & 83 & 109 \\
\hline Cambine & & 2005 & \multicolumn{2}{|c|}{-} & _ & 51 & 84 \\
\hline Massinga & & 2005 & \multicolumn{2}{|c|}{ _ } & _ & 120 & 136 \\
\hline Homoine & & 2005 & \multicolumn{2}{|c|}{ _ } & _ & 18 & 36 \\
\hline Panda & & 2005 & \multicolumn{2}{|c|}{ 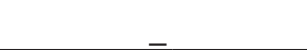 } & _ & 11 & 19 \\
\hline Chimoio & Manica & 2006 & & _ & _ & 93 \\
\hline $\begin{array}{l}\text { Ilha de Moçam- } \\
\text { bique }\end{array}$ & Nampula & 2005 & \multicolumn{2}{|c|}{ - } & - & 63 & 143 \\
\hline Songo & \multirow[t]{2}{*}{ Tete } & 2003 & \multicolumn{2}{|c|}{46} & 46 & 48 & 47 \\
\hline D. Bosco & & 2002 & \multicolumn{2}{|c|}{179} & 179 & 141 & 110 \\
\hline N'Cauma & Niassa & 2005 & \multicolumn{2}{|c|}{ _ } & _ & 63 & 49 \\
\hline \multicolumn{3}{|c|}{ Subtotais } & \multicolumn{2}{|c|}{719} & 719 & 987 & 1352 \\
\hline \multicolumn{3}{|c|}{ Totais } & \multicolumn{5}{|c|}{3618} \\
\hline
\end{tabular}

Fonte: (AZEVEDO e ABREU, 2007, p. 30)

1 Nesta coluna os dados surgem acumulados, uma vez que houve escolas que seguiram o novo modelo curricular e pedagógico sem que se tivesse ainda verificados a sua institucionalização. 
Salienta-se que o ensino técnico é caracterizado e diferenciado dos outros subsistemas do ensino pela sua função social de:
a) Assegurar a formação integral dos jovens e trabalhadores preparando- -os para o exercício de uma profissão numa especialidade, mas sempre dentro das exigências qualitativas e quantitativas da planificação e do desenvolvimento da economia e da sociedade; b) Pela ênfase na forma- ção profissional que consiste em dar aos jovens e trabalhadores uma es- pecialidade e desenvolvendo neles capacidades e hábitos profissionais; c) Associar o conhecimento técnico às experiências práticas e à busca de soluções técnicas e tecnológicas; d) Vincular as escolas técnicas e institu- tos com os sectores produtivos; e) Pelo carácter terminal da formação (a formação geral e básica confina- -se às exigências da educação técni- co-profissional, sem perderem a sua estrutura e solidez científicas; os gra- duados de cada nível incorporam-se prioritariamente nos serviços e na produção; o prosseguimento dos es- tudos sem abandonar o exercício da profissão) (AFRIMAP, 2012, p. 117).

O ingresso no Ensino Técnico Básico (ETB) tem como requisito a conclusão do Ensino Primário Geral ou para adultos ou do Ensino Elementar Técnico-Profissional, com a duração de dois a quatro anos, conferindo um nível escolar correspondente ao $2^{\circ}$ nível do Subsistema de Educação Geral e permitindo o ingresso ao $3^{\circ}$ nível de qualquer dos subsistemas do Sistema Nacional de Educação e Médio (ETM) com as especializações do comércio, indústria e agricultura, saúde e pesca. Esse subsistema tem como população alvo: os jovens em idade escolar e pré-laboral. $\mathrm{Na}$ mesma ordem de ideia, o Plano Estratégico da Educação 2012/2016 vem salientar o seguinte:
A Educação Profissional inclui o ETP, sob tutela do MINED e liderado pela DINET, e abrange os níveis básico (após a $7^{\mathrm{a}}$ classe) e médio (após a $10^{\mathrm{a}}$ classe). Os provedores deste tipo de ensino são públicos e privados. A Educação Profissional inclui também a Formação Profissional de curta duração, em primeiro lugar sob tutela do Ministério de Trabalho e liderada pelo INEFP. Os seus provedores são públicos e privados. (PLANO ESTRATEGICO DA EDUCAÇÃO, 2012-2016, p. 90).

Por sua vez, oEnsino Técnico Médio faz-se após a conclusão do $2^{\circ}$ nível dos subsistemas de Educação Geral, de Educação de Adultos ou de Educação Técnico-Profissional, com duração de dois a quatro anos, concedendo um nível escolar equivalente ao $3^{\circ}$ nível do subsistema de educação Geral e oportunizando o ingresso no Subsistema de Educação Superior ou no nível Superior do Subsistema de Formação de Professores (AFRIMAP; 2012).

Com a guerra de década 80, entre o Governo de Moçambique e a Renamo, ${ }^{1}$ que desestabilizou o país fez que a economia ficasse estagnada e houve também muita saída dos técnicos qualificados para outros países, deixando o Ensino Técnico com grandes problemas. Na mesma discussão, Macamo (2015) diz o seguinte:

A introdução de novas qualificações, do ensino baseado em competências no ensino técnico-profissional, a forte ligação deste subsistema com o sector produtivo, o desenho e implementação de um sistema de garantia de qualidade para as novas qualificações, são ações importantes resgatadas para tornar o ensino mais credível. O sucesso na implementação de um novo sistema de educação baseado em competências pode confirmar a assunção de que, no mercado de

Resistência Nacional de Moçambique 
trabalho, são igualmente importantes os conhecimentos, as habilidades e a atitude dos profissionais, ou seja, os vários saberes (saber, saber fazer, e saber ser e estar).

Por outro lado, o desenho curricular baseado em competências permite, também, que os estudantes obtenham retorno imediato sobre o que estão efetivamente a aprender e percebam, com mais clareza, a importância destas competências para a sua vida pessoal e profissional. $\mathrm{O}$ ensino baseado em competências, por ser normalmente mais dispendioso do que o ensino baseado em objetivos de aprendizagem, trouxe um desafio adicional para as escolas, que é o desafio da sustentabilidade. Esta sustentabilidade pode ser alavancada pela oferta de serviços ao mercado, o que tem um triplo papel: por um lado, forçar a escola a transformar-se num centro produtivo, condição necessária para um provedor de ensino baseado em competência; por outro, gerar receitas para a escola e, ainda, permitir testar a relevância das competências através da oferta de serviços ao mercado, que assentam nessas mesmas competências (MACAMO, 2015, p. 28).

Contudo, há que ter em conta que a educação profissional ancorada em competências e de qualidade implica uma série de mudanças e de investimentos radicais em relação à situação atual deste subsistema de educação. Essa reforma requer grandes investimentos, tendo em conta que a situação orçamental do país é de dependência externa, pelo menos em 50\% do seu orçamento total. Esse fator alia-se ao fato de o Governo não disponibilizar de meios para investir num tipo de educação adequada para o seu povo. Ficando a critério dos investidores externos o poder de imposição.
$\mathrm{Na}$ tentativa de dar resposta aos desafios da competitividade de Moçambique, tomando também em consideração o processo de integração regional na Comunidade para o Desenvolvimento da África Austral (SADC), o governo, por meio do Ministério da Educação, iniciou, em 2006, a Reforma da Educação Profissional (REP). O objetivo dessa reforma é de instruir cidadãos profissionalmente competentes, de modo a desenvolver uma economia competitiva.

Como havia já referido, que em 2006 o Ministério da Educação iniciou a REP, com o lema: "Educação para o trabalho, Competência para a Produção, Desenvolvimento para o País", em que sua implementação está em um período compreendido de quinze anos (2006 - 2020). Portanto, a REP é um plano que se comporta em três fases, nomeadamente:

a) A fase piloto, isto compreendido no período entre 2006 a 2011;

b) A fase de expansão, que foi até o final do ano de 2016;

c) A fase de consolidação, que vai até 2020.

Não obstante, que o PIREP, ${ }^{2}$ sendo uma estratégia de Reforma da Educação da ETP, assenta em quatro grandes componentes:

I. Reforma do Sistema e Desenvolvimento Institucional (incluindo o estabelecimento de um Conselho Nacional para a Formação (CNF) e sistemas sustentáveis para o financiamento e gestão da ETP; o CNF criará um quadro para assegurar o envolvimento de ONGs, instituições do sector público e privado, bem como dos empregadores e sindicatos, na reforma);

II. Desenvolvimento de um sistema da ETP baseado em padrões de competência, incluindo a avaliação e certificação;

2 O Programa Integrado de Reforma da Educação Profissional (PIREP) constitui a fase piloto e tem como lema: "Educação para o trabalho, competências para a produção, desenvolvimento para o país". 
III. Melhoria da qualidade, por via da formação de professores, do fornecimento de materiais de ensino adequados, equipamento e infraestruturas físicas, o estabelecimento de serviços de orientação dos alunos e reforço da capacidade de gestão das instituições da ETP (assim como a capacidade de planear e gerir o impacto do HIV/SIDA nos professores e alunos);

IV. Criação de um fundo para o desenvolvimento de capacidades (FUNDEC) para estimular a emergência de programas de formação inovadores e de alta qualidade. (PLANO ESTRATÉGICO DE EDUCAÇÃO E CULTURA, 2006/11, p. 41).

Assim sendo, "tendo a REP sido um processo de consulta e parceria com os representantes do sector produtivo, das organizações sindicais, da sociedade civil e parceiros internacionais várias questões se podem colocar e têm sido colocados" (PINTO, 2012, p. 10).

Para a execução da REP foram criadas as seguintes estruturas: CIREP - Comissão Interministerial da Reforma da Educação Profissional, com funções de orientação política e presidida pelo primeiro-ministro; COREP Comissão Executiva da Reforma da Educação Profissional, multissetorial, de competências executivas e deliberativa; UI - Unidade de Implementação, principal órgão de execução das políticas, e - Grupo de Aconselhamento, que tem competências consultivas de apoio técnico e interação ao nível da UI e que integra os parceiros da cooperação e as agências doadoras (PINTO, 2012, p.137).

Nesta mesma senda, a REP é uma tentativa de dar resposta aos desafios da competitividade de Moçambique, tomando também em consideração o processo de integração regional na SADC. Ainda na mesma perspectiva, Brouwer e Brito (2010) salientam o seguinte:

Num mundo cada vez mais global e com o país melhor integrado na Re- gião Austral, os graduados da educação profissional moçambicanos de Mavago têm de competir, em pé de igualdade, pelos postos de trabalho não só com os graduados da Cidade de Maputo mas também com os graduados do Botswana, África do Sul, China ou de qualquer outro país do mundo. Só assim poderemos desenvolver o país de forma sustentável e quebrar, de uma vez por todas, o ciclo da pobreza através da criação de emprego, incremento da atividade produtiva e inovação, bem como da criação da riqueza para o bem-estar dos moçambicanos (BROUWER e BRITO, 2010, p.12).

Por sua vez, Pinto (2010) vem salientar que a filosofia do PIREP aponta para a transformação da provisão do (ETP) num sistema orientado pela procura, construído num quadro de formação modular com cursos ancorados em padrões de competência e firme num Sistema Nacional de Padrões, o qual deverá ser reconhecido pelos empregadores e pela sociedade civil. Para isso, destaca-se entre seus objetivos o estabelecimento de um sistema de educação profissional integrado, coerente, flexível e orientado para a procura do mercado de trabalho, e que contará com o envolvimento de todos os parceiros sociais.

A fim de garantir qualidade na reforma, o setor produtivo deve assumir a liderança na definição e aprovação de unidades de competências, das qualificações e programas, oferecer experiências no local de trabalho e estágios para os estudantes, apoiar na avaliação externa dos estudantes e desenvolver parcerias com os provedores de formação, ou por outra:

Nas parcerias com o setor produtivo a reforma propõe que as novas qualificações estejam de acordo com os requisitos da indústria, sejam baseadas em padrões de ocupa- 
ção da indústria que definem competências e em unidades contendo elementos de competência, desenvolvidas em módulos de aprendizagem (módulos vocacionais, eletivos e de competências genéricas) que compõem uma qualificação que permita flexibilidade na lecionação, dê crédito à aprendizagem anterior do estudante, permita a acumulação de crédito de módulos concluídos que sejam avaliados de acordo com as unidades nacionais de competência, que possua medidas de garantia de qualidade para validar as unidades de competência e o seu grau de alcance, se ajuste ao novo Quadro Nacional de Qualificações Profissionais e que desenvolva uma forte parceria entre o setor produtivo e a educação (PIREP, 2008, apud PINTO, 2012, p. 139).

\section{ObJetivos do ENSINO TÉCNICO- PROFISSIONAL EM MoÇAMbIQUe}

De acordo com a Política Nacional de Educação e Estratégias de Implementação, promulgada pelo Conselho de Ministros da República de Moçambique (Resolução n 8/95 de 22 de agosto de 1995), os seguintes objetivos são previsto para o Ensino Técnico-Profissional:

Assegurar a formação integral e técnica dos jovens em idade escolar, de modo a prepará-los para o exercício de uma profissão; b) Desenvolver nos jovens as qualidades básicas de personalidade, em particular, educando-os a assumir uma atitude correta perante o trabalho; c) Desenvolver capacidades de análise e síntese, de investigação e inovação, de organização e direção científica do trabalho; d) Desenvolver conhecimentos sobre a saúde e nutrição e a proteção do ambiente (MOÇAMBIQUE, 1995, p. 182).
Mas de acordo com o Plano Estratégico a Educação, 2012-2016, os objetivos do Ensino Técnico-Profissional trazem consigo novas ideias, que são:

a) Uma resposta diversificada à demanda dos sectores económicos prioritários e emergentes; b) A expansão do subsistema ETP, entendida como resposta crucial do Governo á redução da pobreza e ao aumento de oportunidade de trabaIho, no sector formal e informal da economia (PLANO ESTRATÉGICO A EDUCAÇÃO, 2012-2016, p. 12)

\section{Avanços do ensino TÉCNICO- PROFISSIONAL EM MOÇAMBIQUE}

Apesar de alguns recuos em determinados aspectos, podemos considerar que o ETP tem evoluído bastante nestes últimos anos. Desde 2012, houve progresso, considerando o aspecto da taxa de aproveitamento dos institutos médios. Também houve evolução no que diz respeito à implementação das ações prioritárias que vêm emanando nos planos estratégicos, expansão da formação ancorada em competências, a formação e capacitação dos professores, equipamento das novas instituições, e por último a recente aprovação do pacote legislativo da Educação Profissional pelo Conselho de Ministros, como ilustram os quadros 2 e 3. Há de salientar-se, também, a falta do pessoal técnico em todos os níveis do subsistema para melhor responder aos desafios da Reforma da Educação Profissional (DESEMPENHO DO SECTOR DA EDUCAÇÃO, 2013).

De acordo com o Plano de Educação, o número de alunos do Ensino Técnico-Profissional cresceu numa média de $25 \%$, isto entre os anos de 2012 e 2014. Esse progresso foi notório devido à política de transformação das escolas básicas em escolas de nível médio e profissionais, além da implantação de seis novas escolas, conforme registros constantes nos quadros 4 e 5 , que estão adiante no texto. 
Nessa mesma senda, é de referir que no campo contratação, formação e capacitação de professores houve melhorias, ou seja:

Em 2013 houve progressos na implementação da estratégia de recrutamento, formação e capacitação dos professores para o ETP. Foram recrutados 152 novos docentes (...). Iniciou a formação de professores do Certificado $B$ em parceria com a Itália e, no âmbito da parceria com Portugal, foram formados 19 professores para as
Escolas Profissionais. Foram ainda capacitados professores em exercício na Alemanha (24), e realizou-se a capacitação pedagógica dos professores dos ramos agrários, industrial e comercial, bem como a capacitação na área tecnológica. Ainda, receberam capacitação em CBT em 2013 o que cumulativamente eleva o número de professores que receberam formação no uso das novas metodologias de ensino para mais de 1.000 (DESEMPENHO DO SECTOR DA EDUCAÇÃO, 2013, p. 42).

Quadro 2: Alunos no Ensino Técnico Profissional, público e privado, 2011-2013

\begin{tabular}{|c|c|c|c|c|c|c|c|c|c|c|c|c|c|}
\hline \multirow{2}{*}{\multicolumn{3}{|c|}{$\begin{array}{l}\text { Nível e tipo de ensino } \\
\text { M } \\
\text { HM }\end{array}$}} & \multicolumn{3}{|l|}{2011} & \multicolumn{3}{|c|}{2012} & \multirow{2}{*}{$\begin{array}{l}2012 / \\
2011 \\
\text { HM }\end{array}$} & \multicolumn{3}{|c|}{2013} & \multirow{2}{*}{$\begin{array}{l}2013 / \\
2012\end{array}$} \\
\hline & & & \multirow{2}{*}{$\begin{array}{l}\% \mathrm{M} \\
5.693\end{array}$} & \multirow{2}{*}{$\begin{array}{l}M \\
1.6386\end{array}$} & \multirow{2}{*}{\begin{tabular}{|l|} 
HM \\
$35 \%$ \\
\end{tabular}} & \multirow{2}{*}{\begin{tabular}{|l|}
$\% \mathrm{M}$ \\
5.251 \\
\end{tabular}} & \multirow{2}{*}{$\begin{array}{l} \\
14.967\end{array}$} & \multirow{2}{*}{$\begin{array}{l}M \\
35 \% \\
\end{array}$} & & \multirow{2}{*}{$\begin{array}{l}\% \mathrm{M} \\
4.726 \\
\end{array}$} & & \multirow{2}{*}{$\begin{array}{l}33 \% \\
29 \% \\
45 \%\end{array}$} & \\
\hline Profissi & onal & Diurno & & & & & & & $-9 \%$ & & 14.119 & & $-6 \%$ \\
\hline \multirow[t]{5}{*}{ Básico } & Público & Noturno & 1.731 & 5.626 & $31 \%$ & 1.181 & 4.152 & $28 \%$ & $-26 \%$ & 959 & 3.320 & \multirow{2}{*}{$\begin{array}{l}0 \% \\
27 \%\end{array}$} & $-20 \%$ \\
\hline & \multirow[b]{2}{*}{ Privado } & Diurno & 102 & 213 & $48 \%$ & 148 & 389 & $38 \%$ & $83 \%$ & 155 & 344 & & $-12 \%$ \\
\hline & & Noturno & 6 & 49 & $12 \%$ & 5 & 50 & $10 \%$ & $2 \%$ & & & \multirow{2}{*}{$\begin{array}{l}33 \% \\
35 \% \\
30 \%\end{array}$} & $-100 \%$ \\
\hline & $\begin{array}{l}\text { Outros } \\
\text { Públicos }\end{array}$ & Diurno & 22 & 90 & $24 \%$ & 48 & 177 & $27 \%$ & $97 \%$ & 39 & 144 & & $-19 \%$ \\
\hline & \multicolumn{2}{|c|}{ Total } & 7.554 & 22.364 & $34 \%$ & 6.633 & 19.735 & $34 \%$ & $-12 \%$ & 5.879 & 17.927 & \multirow{5}{*}{$\begin{array}{l}55 \% \\
47 \% \\
38 \%\end{array}$} & $-9 \%$ \\
\hline \multirow{5}{*}{ Médio } & \multirow[b]{2}{*}{ Público } & Diurno & 1.803 & 6.258 & $29 \%$ & 2.015 & 6.406 & $31 \%$ & $2 \%$ & 2.801 & 8.047 & & $26 \%$ \\
\hline & & Noturno & 1.384 & 4.092 & $34 \%$ & 1.390 & 4.274 & $33 \%$ & $4 \%$ & 1.450 & 4.759 & & $11 \%$ \\
\hline & \multirow{3}{*}{ Privado } & Diurno & 1.449 & 2.830 & $51 \%$ & 1.093 & 2.120 & $52 \%$ & $-25 \%$ & 1.793 & 3.247 & & $53 \%$ \\
\hline & & Noturno & 362 & 733 & $49 \%$ & 343 & 698 & $49 \%$ & $-5 \%$ & 398 & 850 & & $22 \%$ \\
\hline & & Total & 4.998 & 13.913 & $36 \%$ & 4.841 & $13.49836 \%$ & $36 \%$ & $-3 \%$ & 6442 & 16.903 & & $25 \%$ \\
\hline
\end{tabular}

Fonte: (Relatório de Desempenho do Sector da Educação, 2013, p. 41). 


\section{Quadro 3: Progresso do Ensino Técnico-Profissional}

\begin{tabular}{|c|c|c|c|c|c|c|c|}
\hline Programa & \multicolumn{7}{|c|}{ Ensino Técnico-Profissional } \\
\hline Objetivo Geral & \multicolumn{7}{|c|}{ Melhorar o acesso, a relevância e a qualidade do ETP para o desenvolvimento do pais } \\
\hline \multirow[t]{3}{*}{$\begin{array}{l}\text { Indicador de } \\
\text { Impacto }\end{array}$} & \multicolumn{5}{|c|}{$\begin{array}{l}\text { \% de graduados absorvidos no mercado de trabalho de } \\
\text { acordo com a sua formação }\end{array}$} & Base (2011) & $\begin{array}{l}\text { Meta } \\
(2016)\end{array}$ \\
\hline & \multicolumn{5}{|c|}{ Graduados do novo sistema de qualificação } & $27 \%$ & $60 \%$ \\
\hline & \multicolumn{5}{|c|}{ Graduados de sistema antigo } & & \\
\hline \multirow[t]{2}{*}{ Objetivos Estratégicos } & \multirow{2}{*}{\multicolumn{2}{|c|}{ Indicador de Resultado }} & \multirow{2}{*}{$\begin{array}{l}\text { Base } 2011 \\
2012\end{array}$} & \multicolumn{2}{|c|}{ Valor observado } & \multirow[t]{2}{*}{ Meta 2013} & \multirow[t]{2}{*}{ Avaliação } \\
\hline & & & & 2013 & & & \\
\hline \multirow{4}{*}{$\begin{array}{l}\text { Aumentar o } \\
\text { acesso e a retenção } \\
\text { no ETP, prestando } \\
\text { particular atenção } \\
\text { às disparidades } \\
\text { geográficas e de } \\
\text { gênero }\end{array}$} & \multirow[t]{4}{*}{$\begin{array}{l}\text { Número de jovem e } \\
\text { adultos no sistema }\end{array}$} & $\begin{array}{l}\text { Escola } \\
\text { profissionais }\end{array}$ & 7.662 & 7871 & 9.496 & 2.675 & Atingida \\
\hline & & $\begin{array}{l}\text { Escolas } \\
\text { Básicas }\end{array}$ & 22.364 & 19735 & 17.927 & 23.410 & Atingida \\
\hline & & $\begin{array}{l}\text { Instituto } \\
\text { Médios }\end{array}$ & 13.913 & 13498 & 16.903 & 13384 & Atingida \\
\hline & & $\begin{array}{l}\text { Cursos não } \\
\text { Formais de } \\
\text { Curta duração }\end{array}$ & $\begin{array}{l}1.000 \\
\text { (previsão } \\
\text { 2011) }\end{array}$ & 1954 & 3250 & 2.600 & Atingida \\
\hline \multirow{3}{*}{$\begin{array}{l}\text { Garantir que os } \\
\text { graduados do } \\
\text { ETP tenham uma } \\
\text { Formação de } \\
\text { qualidade e } \\
\text { relevante para } \\
\text { o mercado formal } \\
\text { e informal }\end{array}$} & \multirow{3}{*}{$\begin{array}{l}\text { Taxa de aproveita- } \\
\text { mento por } \\
\text { cada nível e sistema } \\
\text { de ensino }\end{array}$} & $\begin{array}{l}\text { Escola } \\
\text { profissionais }\end{array}$ & $75,7 \%$ & $75 \%$ & $68,8 \%$ & $79 \%$ & $\begin{array}{l}\text { Não } \\
\text { atingida }\end{array}$ \\
\hline & & $\begin{array}{l}\text { Escolas } \\
\text { Básicas }\end{array}$ & $63,3 \%$ & $53 \%$ & $53,0 \%$ & $67,0 \%$ & $\begin{array}{l}\text { Não } \\
\text { atingida }\end{array}$ \\
\hline & & $\begin{array}{l}\text { Instituições } \\
\text { de nível } \\
\text { médio }\end{array}$ & $73,2 \%$ & $72 \%$ & $76,3 \%$ & $77 \%$ & $\begin{array}{l}\text { Não } \\
\text { Atingida } \\
\text { com } \\
\text { progresso }\end{array}$ \\
\hline $\begin{array}{l}\text { Melhorar a gestão } \\
\text { Coordenação do } \\
\text { Sistema, } \\
\text { Envolvendo o } \\
\text { Sector produtivo } \\
\text { de forma } \\
\text { particular }\end{array}$ & \multicolumn{2}{|c|}{$\begin{array}{l}\text { Número de escolas que } \\
\text { Implementam instrumentos de } \\
\text { gestão de qualidade }\end{array}$} & 5 & 14 & 19 & 19 & Atingida \\
\hline
\end{tabular}

Fonte: (Relatório de Desempenho do Sector da Educação, 2013, p. 66). 


\section{OS DESAFIOS DO ENSINO TÉCNICO (SABER FAZER) EM MoÇAMbiQue}

O Ensino Técnico-Profissional prepara os alunos para a transição da escola para o mundo de trabalho, através do desenvolvimento de conhecimentos e de competências para um desempenho adequado nas várias profissões. O desenvolvimento vertente é crucial para uma economia em crescimento, que solicita competências cada vez mais complexas e especializadas. Isto implica a criação de um de qualidade, que responda com graduados competentes e suficientes às diversas necessidades do sector produtivo" (PLANO ESTRATÉGICO DA EDUCAÇÃO, 2012-2016, p. 90).

O problema central do ETP está no fato de não possuir um subsistema que reúna as condições necessárias para satisfazer, qualitativa e quantitativamente, as necessidades atuais e futuras do mercado de trabalho formal e informal (PINTO, 2010).

Segundo Brouwer e Brito (2010), o Ensino Técnico tem enormes desafios, por exemplo:

criação um órgão regulador forte para o sistema da educação profissional o mais rápido possível por forma a implementar o Quadro Nacional de Qualificações Profissionais (QNQP) e os mecanismos de garantia de qualidade que vão trazer a credibilidade desejada pelo sistema conjugado com envolvimento formal dos empregadores na estrutura de governação dos instituto do ensino profissional (IEP), como já acontece nos instituto superior profissional (ISP). Melhorar a articulação com o ensino superior e geral, e a ligação entre os empregadores e as IEP. Unificar o sistema de educação para emprego com o sistema de ensino técnico assim como a educação não-formal (que abrange a maioria dos profissionais moçambicanos), através da implementação do QNQP e seus sistemas associados. E por ultimo descentralização da gestão do sistema de educação para que ele seja mais eficiente e responda às necessidades locais, reforçando as funções e atribuições de IEP no que diz respeito à gestão de todo o processo de ensino/aprendizagem, contactos com os empregadores para estágios, mobilização de fundos (BROUWER, BRITO, 2010, p. 285).

Outro fator que torna a ETP menos eficiente é o fato de os seus graduados terem reduzido a possibilidade de empregabilidade, por isso muitos deles recorrem ao autoemprego, o que é agravado pelas fraca qualificação dos instrutores, pois os melhores instrutores acabam por abandonar o ensino em troca de emprego melhor remunerado.

No que se refere aos custos por aluno, a ETP possui um custo relativamente alto, 2,5 vezes superior ao custo por aluno numa instituição do ensino secundário geral. Porém, um dos fatores fundamentais para o sucesso deste subsistema de ensino é a qualificação e competência técnica do professor, o que eleva os custos por aluno.

Podemos dizer que um dos grandes desafios de momento é encontrar uma forma que garanta, por um lado, a integridade do sistema; por outro, criando a flexibilidade necessária mediante o estabelecimento de um sistema de financiamento e seriedade adequado. Tomando em conta que o ensino primário, em nível das autarquias, deve ser assumido como responsabilidade dos Conselhos Municipais, esta oportunidade pode ajudar a alavancar a reconfiguração que se pretende no sistema (MACAMO, 2015). 
Outro desafio é que Ensino Técnico deve promover a coesão entre a instituição educativa (escolar ou comunidade escolar) e o meio envolvente (comunidade geral) onde esta se encontra inserida. Para que isso ocorra, é imprescindível a articulação de esforços para definir o sentido da ação educativa e satisfazer os anseios e as necessidades dos alunos, das suas famílias, da escola e da comunidade em geral (PINTO, 2012).

Em razão disso, pode-se concluir que o setor de educação, sobretudo a este nível, possui grandes desafios, desde a construção e reabilitação de infraestruturas até a formação do corpo docente.

Quadro 4: Número de escolas no Ensino Técnico-Profissional

\begin{tabular}{|c|c|c|c|c|c|c|}
\hline Ano & $\mathbf{2 0 0 4}$ & $\mathbf{2 0 0 5}$ & $\mathbf{2 0 0 6}$ & $\mathbf{2 0 0 7}$ & $\mathbf{2 0 0 8}$ & $\mathbf{2 0 0 9}$ \\
\hline ETE & 11 & 16 & 16 & 13 & 23 & 36 \\
\hline ETB & 25 & 25 & 25 & 27 & 27 & 28 \\
\hline ETM & 7 & 7 & 8 & 8 & 12 & 19 \\
\hline
\end{tabular}

Fonte: (AfriMap, 2012, p. 125)

Quadro 5: Número de Escolas no Ensino Técnico-Profissional

\begin{tabular}{|c|c|}
\hline Ano & $\mathbf{2 0 1 5}$ \\
\hline ETE & 16 \\
\hline ETB & 29 \\
\hline ETM & 38 \\
\hline
\end{tabular}

Fonte: Autor (2018)

As ilações que se pode tirar a partir dos quadros 4 e 5 são: a) até 2007 o crescimento das escolas do ensino técnico profissional tende a se manter e a reduzir devido à degradação de algumas escolas que não chegam a ser reabilitadas. Pese embora, o fato de com a reforma iniciada em 2006 ter permitido a manutenção e aparelhagem de algumas escolas, assim como a construção de novas salas, o número das salas de aulas ainda se encontra longe dos anseios do Ministério da Educação de tornar este um nível competitivo internacionalmente.

Fraca qualidade e disponibilidade de recursos humanos, desmotivação e carência de materiais didáticos, de infraestruturas, limitado acesso às oportunidades educativas, baixa qualidade de ensino e o alto custo da expansão do acesso e da melhoria da qualidade são também alguns dos sintomas verificados na educação técnica em moçambicana (PINTO, 2010).

Nessa mesma linha de raciocínio, podemos encontrar algumas causas do problema, como: o limitado acesso dos cidadãos ao ETP (absorveu em 2001 apenas 1\% da população em idade escolar, o nível médio só existe em sete províncias e a taxa de participação da menina era apenas de $20 \%$ ), a baixa eficiência (taxa média de aprovação de 50\% e taxa média de repetência de 30\%); a baixa eficácia (apenas 20\% das escolas reúnem boas condições) (MINISTÉRIO DE EDUCAÇÃO, 2006).

Outro problema que podemos considerar central do ETP é a questão da insuficiência no provimento de professores; inadaptação dos currículos às atuais necessidades do mercado de trabalho, pela fraca capacidade prática e qualificações dos alunos, a pouca afluência no português e o conhecimento de línguas estrangeiras, falta de capacidade de gestão/ supervisão, a pouca autonomia e má gestão das instituições, orçamentos insuficientes, altas taxas de repetição, de desistência e insucesso e o elevado custo por aluno do ETP; a alta proporção de ingresso de professores sem formação pedagógica; a distância entre o local do trabalho e a sua origem de proveniência. $\mathrm{E}$ mais em diante iremos analisarmos alguns destes desafios com mais pormenores. 
Entretanto, existe um desajustamento entre a procura e a oferta de profissionais em termos de níveis, como em termos de competências e conhecimento. Registra-se falta de professores com a formação adequada para atuação nos domínios das disciplinas técnicas e profissionais, insuficiência que compromete também a possibilidade de realizar outras ofertas de qualificação profissional, como cursos de curta duração. E isto tem levado muitos professores a assegurar simultaneamente disciplinas da formação técnica e geral. Ou seja, sendo, o sistema de educação técnico-profissional, que é responsável pela moldagem do perfil de habilidades exigidas no mercado de emprego, foi lento na resposta às demandas de mudança de mercado no setor formal. As pesquisas sobre o emprego e estudos de mercado de trabaIho nas empresas do setor formal mostram que há uma ligação inadequada entre a capacidade humana disponível e as crescentes necessidades do mercado de emprego, que requer trabalhadores mais qualificados (DINET/COREP, 2008).

Outro desafio é o recrutamento de professores sem a formação pedagógica, ou seja, "a prática tem sido de recrutamento de professores jovens, recém-saídos do ensino técnico, sem a formação e experiência pedagógica, tendo as direções províncias argumentado que procuram selecionar os que se revelaram como os melhores estudantes no ensino técnico" (CASTRO e MACHADO, 2011, p. 38). E segundo Pinto (2010), dentro do quadro do pessoal docente, em 2000 somente $13,8 \%$ dos docentes tinham formação superior e $65,55 \%$ possuíam formação psicopedagógica. Isso tendo em conta que, atualmente para o ETP, não existe qualquer sistema de capacitação para os professores e gestores, pois desapareceram os Institutos Pedagógicos para a sua formação especializada, nos princípios da década de 90. Desde então, a formação de professores para o ETP permanece estagnada.
Ainda nessa mesma discussão, Pinto (2010) diz que vários cenários ou projetos estão a ser estudados, por exemplo aproveitar as instituições de ETP do nível médio, pelo menos uma em cada região principal do país, para a formação inicial de professores ou aceitar proposta da Comunidade Salesiana em Moçambique que se propõe a construir um campus de formação de professores. Isto é:

Como no Ensino Técnico é importante que o corpo docente seja constituído, na sua maioria, por técnicos com formação e experiência profissional, procura-se desenvolver mecanismos que favoreçam o recrutamento de docentes a partir das empresas, como medida de emergência para combater a falta de formação de professores para o ETP. Prevê-se organizar cursos de formação inicial com o objectivo de conferir conhecimentos nos domínios psicopedagógicos e metodologias de ensino (PINTO, 2010, p. 11).

Entretanto, deve haver maior investimento por parte das direções provinciais na oferta de estruturas e possibilidade no componente de formação pedagógica.

De acordo com o quadro 6 , ainda temos grande déficit de pessoal docente com a formação Psicopedagógica. Destaca-se que é importante incluir essa formação na matriz curricular dos cursos técnicos, isto tendo em conta que os alunos que neles se formam têm sido recrutados para dar aulas não somente nas EP, como também nas escolas de formação geral do país.

Nessa mesma senda, podemos inferir que a formação de professores, a par da investigação e desenvolvimento curricular, deve ser um dos pontos centrais do governo, pois sem eles não é possível transformar a escola e muito menos ter a educação como a alavanca da transformação que se precisa para construção de sociedades sustentáveis, como a moçambicana. (MACAMO, 2015). 
Quadro 6: Perfil docente face à formação psicopedagógica no ano de 2011

\begin{tabular}{|l|c|c|c|}
\hline \multicolumn{1}{|c|}{ Escola } & $\begin{array}{c}\text { Docentes com formação } \\
\text { Psicopedagógica }\end{array}$ & $\begin{array}{c}\text { Docentes em formação } \\
\text { Psicopedagógica }\end{array}$ & Total \\
\hline EP. Moamba & Sd & Sd & Sd \\
\hline EP. S. Francisco Assis & 24 & 22 & 30 \\
\hline EP. D. Bosco & 8 & Sd & Sd \\
\hline EP. Inhamissa & Sd & Sd & Sd \\
\hline EP. Songo & Sd & Sd & 14 \\
\hline EP. Inharrime & Sd & 5 & 31 \\
\hline EP. Ilha de Moçambique & 9 & & 31 \\
\hline EP. Massinga & 14 & 20 & 13 \\
\hline EP. Montepuez & 13 & 8 & 11 \\
\hline EP. Mangunde & 5 & 8 & 46 \\
\hline EP. Mariri & 3 & 26 & 16 \\
\hline EP. Chimoio & 20 & 2 & 11 \\
\hline EP. Ocua & 14 & 4 & 34 \\
\hline EP. Caia & 7 & & \\
\hline
\end{tabular}

Fonte:(CASTRO e MACHADO, 2011: p. 38)

Sd = Sem dados.

\section{CONSIDERAÇÕES FINAIS}

Podemos inferir que a educação tem sido, para as sociedades, um meio pelo qual se transmitem e se conservam os aspectos culturais de um povo de geração em geração, e também de transmissão de conhecimento científico. Nesse sentido, a educação é um eterno processo de aperfeiçoamento, amadurecimento, refinamento das culturas humanas e da ciência. A realidade moçambicana, hoje, chama-nos a refletir sobre a necessidade de uma educação que possa responder às nossas inquietações, pensando sobre a questão de como a escola pode contribuir para a formação de seus membros em nossa sociedade contemporânea. O rumo da educação moçambicana aos nossos dias tende a caminhar num paradigma centralizado no saber fazer, ou seja, ensino técnico profissional.

Entretanto, o Ensino Técnico em Moçambique desempenha um papel preponderante, isto quer em termos socioeconômicos, quer em termos históricos e sendo também muito relevante na promoção social do trabaIho. Os cursos profissionais tendem a corresponder à opção capaz de minimizar as críticas vindas do Ensino Geral, no campo da empregabilidade.

As aplicações desses conhecimentos na vida prática do estudante do Ensino Técnico Profissional só serão possíveis se existirem melhores condições de trabalho, nomeadamente: o foco prático do ensino e a sua conexão ao mundo do trabalho; melhoramento (aparelhagem) de infraestruturas e a existência de um quadro de pessoal docente qualificado, pois, muitos dos professores que lecionam neste subsistema ensino desconhecem os princípios psicopedagógicos que estão subjacentes à organização e ao funcionamento da estrutura curricular por módulos para o desenvolvimento de competências nos cursos profissionais.

Entretanto, deve-se evitar excesso na especialização do Ensino Técnico-Profissional, isto sob risco de estamos a formar, como diz Azevedo (2007) "automáticos programados" 
e não jovens cidadãos construtores do seu futuro, uma realidade em aberto ao longo da vida. Apesar das mesmas escolas do Ensino Técnico possuírem um percurso próprio e uma relativa autonomia que Ihes permite construírem uma cultura própria.

Assim sendo, persistência de Ensino Técnico-Profissional parece uma medida política (empregabilidade) do que responder ao insucesso escolar ou à crise da nossa educação. Pois, atualmente, o governo moçambicano está preocupado com a escassez de mão de obra especializada para satisfazer a demanda dos grandes projetos envolvidos na exploração de recursos minerais, sobretudo gás natural e carvão mineral na região Norte do país, portanto, a persistência na formação Técnico-Profissional é uma das saídas para colmatar esse déficit.

Nesse novo contexto do Ensino Técnico Profissional, é preciso com muita urgência revitalizar esse mesmo ensino, mas isso passa necessariamente pela capacitação dos diretores, introdução de cursos com organização modular, criação de novo modelo de administração, de organização e Gestão do Ensino Técnico-Profissional. Também pelo melhoramento do sistema de orçamento e revisão curricular dos cursos do Ensino Médio dos vários ramos, novos Institutos Médios e cursos de nível médio introduzidos em escolas de nível Básico, reativação e ampliação da rede de Escolas Elementares, reabilitações de infraestruturas e reequipamentos de algumas Escolas Técnicas e várias parcerias entre Escolas, Institutos Técnicos e empresas.

Podemos inferir que as escolas técnicas, sendo parte integrante da comunidade e no meio onde estão inseridas, a comunidade deve intervir na vida escolar, isto apoiando na organização e na procura de soluções para as mais diversas dificuldades, no trabalho educa- tivo e nos desafios. É fundamental para a sobrevivência de toda a comunidade.

Ainda na mesma senda, é preciso não colocar de lado reafirmação da participação do setor produtivo como condição essencial para a implementação da Reforma da Educação Profissional, de modo a qualificar mão de obra alinhada com as necessidades do mercado de trabalho, e por outro, identificar os níveis, canais e procedimentos de concretização das parcerias entre a Educação Profissional e o Setor Empresarial.

É preciso fortificar áreas de oferta de formação, pois vai facilitar e facultar uma especialização terminal e obtenção de um primeiro emprego, mas isso não implica, como havíamos referido, afunilar demasiado os domínios de formação que se oferece aos adolescentes. E para melhor viabilizar esse projeto ou ideia de especificações terminais, deve-se criar uma organização curricular. Como diz Brouwer e Brito (2010), é necessário que o Ensino Técnico-Profissional recupere o prestígio e a credibilidade, de forma que a sociedade veja, nesta formação, uma alternativa viável ao Ensino Geral. A introdução de novas qualificações, do ensino ancorado em competências no Ensino Técnico-Profissional, a forte ligação desse subsistema com o setor produtivo e o desenho e implementação de um sistema de garantia de qualidade para as novas qualificações, são ações importantes para se resgatar essa credibilidade.

Por último, temos de advogar a importância de estágios profissionais, e os mesmos devem ser devidamente acompanhados pela escola, ou seja, as escolas devem criar condições de parcerias com outras instituições, a fim de garantir aos alunos a realização de estágios, possibilitar que os alunos realizem encomendas de trabalho e para a criação de pequenas unidades de produção autônomas e geridas pelos alunos. 


\section{REFERÊNCIAS}

AFRIMAP. Moçambique: a prestação efetiva de serviços públicos no sector de educação. África do Sul, 2012.

AZEVEDO, J. \& ABREU, J. M. Ensino Profissional em África: Falácia ou Oportunidade? O Caso das Escolas Profissionais em Moçambique. Revista Portuguesa de InvestigaçãoEducacional. 5, 5-42, 2007.

BROUWEE, R.; BRITO, L. Educação, formação Profissional e Poder. In: (Org.). Desafios para Moçambique. Maputo: IESE, p. 296, 2010.

DELORS, J. Educação, um tesouro a descobrir: relatório para UNESCO da Comissão Internacional sobre Educação para o século XXI. Edições ASA. Portugal, 1996.

DINET/COREP. O Desafio da Reforma de TVET em MOÇAMBIQUE: Metas, Opções e Constrangimentos. Comunicação preparada pela COREP/DINET na conferência ADEA, Maputo, 2008.

GONÇALVES, António Parafino (2015). O papel da educação superior no desenvolvimento socioeconômico e cultural de Moçambique ISTAC, Maputo, 2015.

GOVERNO DE MOÇAMBIQUE. Pobreza Absoluta, (PARPA II), Maputo 2006.

GRAMSCI, A. Cadernos do cárcere. Os intelectuais. O princípio educativo. Jornalismo. Trad. Carlos Nelson Coutinho. Volume 2, Rio de Janeiro: Civilização Brasileira, 2004.

MACAMO, M. Ernesto. Insucesso Escolar em Moçambique: Escola Secundária Graça Machel. Lisboa: UAB, 2015. 123 f. Dissertação (Mestrado em Administração e Gestão Educacional. Departamento de Educação e Ensino a Distância. Universidade Aberta, Lisboa, 2015.

MARX, Karl. Manuscritos Econômico-Filosóficos. Lisboa: Edições 70, 1964.

MINISTÉRIO DE EDUCAÇÃO. Resumo do Relatório do diagnóstico de Ensino Secundário Geral-ESG. Maputo, 2005.

MINISTÉRIO DE EDUCAÇÃO. Plano Curricular do Ensino Secundário Geral (PCESG): Objectivos, Políticas, Estrutura, Plano de Estudos e Estratégia de Implementação. Moçambique, 2007.

MINISTÉRIO DE EDUCAÇÃO. Plano Curricular do Ensino Básico: Objectivos, Política, Estrutura, Plano de estudos e Estratégias de implementação. Maputo, 2008.

MINISTÉRIO DE EDUCAÇÃO. Plano Estratégico de Educação 1999-2003: Combater a exclusão, Renovar a escola. Maputo, 1998.

MINISTÉRIO DE EDUCAÇÃO. Plano Estratégico de Educação e Cultura 2006-2010/11. Maputo, 2006.

MINISTÉRIO DE EDUCAÇÃO. Unidade na Ação: Por uma implementação eficaz do Plano Estratégico da Educação e Cultura-Reforma do Ensino Superior. Ilha de Moçambique, 2008. 
MINISTÉRIO DE EDUCAÇÃO. Estatística da Educação, Levantamento Escolar: Educação Geral: Formação de professores-Ensino Técnico. Maputo, 2009.

MOÇAMBIQUE. Resolução nº 8, de 22 de agosto de 1995. Política Nacional de Educação e Estratégias de Implementação. Boletim da República, Imprensa Nacional de Moçambique, série 1, no 41. p. 186.

PINTO, Ana Paula. A Escola Técnica e a Dinamização do Meio. Livro de Actas do Congresso África e o Mundo (COOPEDU II). Lisboa: CEA e IP, Leiria, 2012.

. As Políticas Nacionais, os Planos Estratégicos de Educação e o Ensino Técnico Profissional em Moçambique. Livro do $7^{\circ}$ Congresso Ibérico de Estudos Africanos (CIEA7). Lisboa: CEA, 2010.

. O Subsistema do Ensino Técnico-Profissional em Moçambique e a Viragem do Século. Atas do Congresso Internacional Saber Tropical em Moçambique: História, Memória e Ciência. Lisboa: IICT, 2012.

Augusto Agostinho Chicava

Doutorado em Educação pela Universidade Federal do Rio Grande Sul (UFRGS). E-mail: augustochicava@yahoo.com.br

Submetido em: 30-5-2018

Aceito em: 11-6-2019 